OPEN ACCESS

Edited by:

Liana Fattore,

Consiglio Nazionale Delle

Ricerche (CNR), Italy

Reviewed by:

Carla Cannizzaro,

Università degli Studi di

Palermo, Italy

Ruben David Baler,

National Institutes of Health (NIH),

United States

Marco Diana,

University of Sassari, Italy

*Correspondence:

Tomáš Páleníček

tomas.palenicek@nudz.cz

Specialty section: This article was submitted to

Addictive Disorders,

a section of the journal

Frontiers in Psychiatry

Received: 26 September 2017

Accepted: 20 December 2017

Published: 10 January 2018

Citation:

Šíchová K, Pinterová N, Židková $M$, Horsley RR, Lhotková E, Štefková K,

Vejmola Č, Uttl L, Balíková M,

Kuchař M and Páleníček T (2018)

Mephedrone

(4-Methylmethcathinone): Acute

Behavioral Effects, Hyperthermic, and

Pharmacokinetic Profile in Rats.

Front. Psychiatry 8:306.

doi: 10.3389/fpsyt.2017.00306
Mephedrone

\section{(4-Methylmethcathinone): Acute Behavioral Effects, Hyperthermic, and Pharmacokinetic Profile in Rats}

\author{
Klára Šíchová1, Nikola Pinterová1,2, Monika Židková3, Rachel R. Horsley', Eva Lhotková1, \\ Kristýna Štefková', Čestmír Vejmola ${ }^{1,2}$, Libor Uttl ${ }^{1,4}$, Marie Baliková3, Martin Kuchař ${ }^{1,5}$ and \\ Tomáš Páleníček ${ }^{1,2 *}$
}

${ }^{1}$ Department of Experimental Neurobiology, National Institute of Mental Health, Klecany, Czech Republic, ${ }^{2}$ Third Faculty of Medicine, Charles University in Prague, Prague, Czech Republic, ${ }^{3}$ Institute of Forensic Medicine and Toxicology, First Faculty of Medicine, Charles University in Prague, Prague, Czech Republic, ${ }^{4}$ Department of Physiology, Faculty of Science, Charles University, Prague, Czech Republic, ${ }^{5}$ Forensic Laboratory of Biologically Active Compounds, Department of Chemistry of Natural Compounds, University of Chemistry and Technology Prague, Prague, Czech Republic

Mephedrone (MEPH) is a synthetic cathinone derivative with effects that mimic MDMA and/or cocaine. Our study in male Wistar rats provides detailed investigations of MEPH's and its primary metabolite nor-mephedrone's (nor-MEPH) pharmacokinetics and bio-distribution to four different substrates (serum, brain, lungs, and liver), as well as comparative analysis of their effects on locomotion [open field test (OFT)] and sensorimotor gating [prepulse inhibition of acoustic startle reaction (PPI ASR)]. Furthermore, in order to mimic the crowded condition where MEPH is typically taken (e.g., clubs), the acute effect of MEPH on thermoregulation in singly- and group-housed rats was evaluated. Pharmacokinetics of MEPH and nor-MEPH after MEPH ( $5 \mathrm{mg} / \mathrm{kg}$, sc.) were analyzed over $8 \mathrm{~h}$ using liquid chromatography with mass spectrometry. $\mathrm{MEPH}(2.5,5$, or $20 \mathrm{mg} / \mathrm{kg}$, sc.) and nor-MEPH (5 mg/kg, sc.) were administered 5 or 40 min before the behavioral testing in the OFT and PPI ASR; locomotion and its spatial distribution, ASR, habituation and PPI itself were quantified. The effect of MEPH on rectal temperature was measured after 5 and $20 \mathrm{mg} / \mathrm{kg}$, sc. Both MEPH and nor-MEPH were detected in all substrates, with the highest levels detected in lungs. Mean brain: serum ratios were 1:1.19 (MEPH) and 1:1.91 (nor-MEPH), maximum concentrations were observed at $30 \mathrm{~min}$; at 2 and $4 \mathrm{~h}$ after administration, nor-MEPH concentrations were higher compared to the parent drug. While neither of the drugs disrupted PPI, both increased locomotion and affected its spatial distribution. The effects of MEPH were dose dependent, rapid, and short-lasting, and the intensity of locomotor stimulant effects was comparable between MEPH and nor-MEPH. Despite the disappearance of behavioral effects within 40 min after administration, MEPH induced rectal temperature elevations that persisted for $3 \mathrm{~h}$ even in singly housed rats. To conclude, we observed a robust, short-lasting, and most likely synergistic stimulatory effect of both drugs which corresponded to brain pharmacokinetics. The dissociation between the duration of behavioral and hyperthermic effects is indicative of the possible contribution 
of nor-MEPH or other biologically active metabolites. This temporal dissociation may be related to the risk of prolonged somatic toxicity when stimulatory effects are no longer present.

Keywords: mephedrone, 4-methylmethcathinone, nor-mephedrone, pharmacokinetics, open field, prepulse inhibition, thermoregulation, Wistar rat

\section{INTRODUCTION}

Mephedrone (4-methylmethcathinone, 4-MMC; MEPH, hereafter), a synthetic derivative of cathinone was first synthetized in 1929 with the aim of developing this compound for therapeutic purposes (1). At the turn of the twenty-first century MEPH was rediscovered by recreationalusers (asaso-called "new psychoactive substance": NPS) and owing to its psychoactive effects, it became widely used as party drug known under the street name "meow meow" (2,3). Based on users' reports, MEPH's effects are very similar to amphetamine, to 3,4-methylenedioxymethamphetamine (MDMA) and to cocaine, or their combination (4-6). MEPH's effects are rapid and of relatively short duration depending on the administration route (intranasal: $\sim 30 \mathrm{~min}$, oral: $\sim 2-3 \mathrm{~h}$ ) $(7,8)$, resulting in a tendency for recreational users to re-dose, as is the case with cocaine $(9,10)$. Prolonged and/or poly-drug use [including "slamming"-intravenous injection of MEPH combined with other drugs (11)] may be associated with adverse psychological (e.g., paranoia, depression, panic attacks), cardiovascular, or renal effects $(12,13)$. Furthermore, at least 90 deaths have been documented where MEPH alone (or its combination with other psychoactive compounds) was implicated (14-17). In 2010, MEPH was classified as a controlled substance in some European countries, and 2 years later in the USA (7). Despite its ban, it has remained a popular recreational drug to this day $(18,19)$.

Mephedrone acts as non-selective monoamine uptake inhibitor and releaser with dopamine transporter: serotonin transporter (DAT: SERT) inhibition ratio being 1.4, which led authors to label MEPH as mixed MDMA-cocaine-like compound (20,21). However, while MEPH's uptake of dopamine (DA) is roughly equivalent to that of serotonin (5-HT), it is (such as MDMA or cathinone) several times more potent at nor-epinephrine transporter (NET) with NET: DAT ratio being approximately 13 (20). MEPH is also active on vesicular monoamine transporters 2 , where its activity is approximately 10 times less potent than MDMA (22). Partly contrasting the transporter studies, according to in vivo microdialysis studies in nucleus accumbens (NAcc), $\mathrm{MEPH}$ had approximately twofold greater effect on 5-HT than DA release $(23,24)$. Furthermore, MEPH also has some activity at serotonin $5-\mathrm{HT}_{2 \mathrm{~A}}$, noradrenaline $\alpha_{1,2}$ and trace amine associated receptor $\left(\mathrm{TAAR}_{1}\right)$. Affinity for DAT together with its high bloodbrain barrier permeability (twofold greater than amphetamine and MDMA) (20) and direct effects on DA in NAcc make MEPH a compound with high addictive potential, which is confirmed by users $(10,20,25,26)$ and by animal studies $(27-29)$. Its strong affinity for NET then might be indicative of cardiovascular toxicity (7).

Mayer et al. (30), using in vitro assays, showed that the phase I metabolites 4-methylcathinone (nor-mephedrone (nor-MEPH) hereafter), 4-hydroxytolylmephedrone (4-OH-MEPH) and dihydromephedrone also have measureable activity at DAT, NET, and SERT, although of these, only nor-MEPH and 4-OH-MEPH at a range meaningful for behavioral tests. Therefore, bioactive metabolites can also contribute to MEPH's effects. However, this was previously confirmed only for nor-MEPH, which displayed in vivo behavioral stimulatory activity (30).

In rodent models, MEPH administration leads to dosedependent increases in locomotion [reviewed in Ref. (7)]. The intensity and duration of these changes is comparable to those observed after the same dose of MDMA, but lesser than amphetamine's effects $(23,24)$. MEPH's effect on sensorimotor gating has only been evaluated in a chronic administration paradigm by Shortall et al. (31); in order to mimic weekend type recreational use of drugs, they administered MEPH $(1,4$, or $10 \mathrm{mg} / \mathrm{kg})$ twice a week on two consecutive days for 3 weeks and tested prepulse inhibition of acoustic startle reaction [PPI ASR; a behavioral operationalization of sensorimotor gating (32)]; $30 \mathrm{~min}$ (min) after the final injection; this yielded no disruptive effect. On the other hand, related drugs, such as MDMA, amphetamine, cocaine, also cathinone itself, and methylone, have shown some disruptive effects in this paradigm (33-39). No information currently exists on MEPH's acute effect nor the effects of its metabolites on PPI.

Studies of MEPH effects on thermoregulation are inconsistent in their results; both hyperthermic (Sprague-Dawley rats $(24,27))$ and hypothermic $(40)$ responses have been documented. Alteration of body temperature is an effect that is dose- and environment-dependent in the case of MDMA and related compounds [e.g., Ref. $(38,39,41,42)]$. In two of our previous studies, we have found that serotonergic compounds, along with severe hyperthermia, can induce profound sweating, particularly when rats are housed in cages in groups $(38,41)$. Group-housing mimics the crowded conditions in clubs where drugs, such as MDMA and MEPH are typically used. It is generally known that the hyperthermia associated with the use of these compounds is one of the key preceding conditions of neurotoxicity as well as of acute somatic toxicity related to serotonin syndrome (43). Therefore detailed examination of dose-related interactions with environmental conditions (such as crowding) is necessary in order to elucidate inconsistencies in MEPH's effects on thermoregulation.

Our main intention was to enrich current knowledge of MEPH by detailed description of the temporal characteristics of its behavioral effects in relation to its pharmacokinetics and bio-distribution and to investigate effects of its major active metabolite nor-MEPH. To describe the temporal profile of behavioral changes, two testing-onsets (5 or $40 \mathrm{~min}$ after drug administration) were used to register both peak and prolonged drug effects. Stimulatory locomotor effects, exploration and/or anxiogenic/anxiolytic potential were tested in the open field test (OFT) and the effects on sensorimotor gating were measured in 
PPI ASR. Alongside this, pharmacokinetic profile of MEPH and nor-MEPH in brain and serum, and their bio-distribution to liver and lungs were established, over $8 \mathrm{~h}$. To evaluate MEPH's effects on thermoregulation under crowded and isolated environmental conditions, rectal temperatures were measured over $8 \mathrm{~h}$ in groups of five rats versus rats housed alone.

\section{MATERIALS AND METHODS}

\section{Animals}

Male outbred Wistar rats (VELAZ, Czech Republic) weighing approximately 180-250 g were housed in pairs under controlled conditions (light/dark arrangement: 12/12 hours, temperature: $22 \pm 2{ }^{\circ} \mathrm{C}$, humidity: $30-70 \%$ ) with ad libitum water and standard diet. In each study, rats acclimatized to the laboratory facility for seven days, with tests performed in the seven days following. Therefore, testing/sampling occurred when rats were approximately 10-11 weeks old (adult) and they were in the laboratory for approximately 10-14 days in total. During the acclimatization period, rats were handled four times and weighed twice. Experiments and measurements were conducted in the light phase of the cycle (between 07:00 and 15:00 h). Experimental groups consisted of 10 individuals, each rat was tested only once, with the exception that to reduce the number of animals used, rats treated by $\mathrm{MEPH} /$ nor-MEPH in behavioral studies were subsequently used for pharmacokinetic sampling. Hence, only eight additional rats were needed (for $30 \mathrm{~min}$ post-drug administration samples).

\section{Drugs and Chemicals}

Mephedrone was purchased via the internet and subsequently purified and converted to MEPH hydrochloride by Alfarma s.r.o. (Czech Republic). The resulting MEPH was certified to be of $99.18 \%$ purity (analyzed by infrared spectroscopy) and also served as a reference standard for pharmacokinetic analyses using liquid chromatography. Nor-MEPH was synthesized at the Department of Organic Chemistry, Faculty of Chemical Technology (University of Chemistry and Technology Prague, Czech Republic) at a purity of 99.18\%. Internal standards MEPH-D7.HCl and nor-MEPH-D7.HCl for quantitative liquid chromatography/mass spectrometry (LC/MS) assays were synthesized at the Department of Organic Chemistry, Faculty of Chemical Technology (University of Chemistry and Technology Prague, Czech Republic). Extraction columns (Bond Elut Certify $50 \mathrm{mg} / 3 \mathrm{ml}$ ) were supplied by Labicom s.r.o., Olomouc. Other chemicals used for laboratory purposes were of analytical grade purity. MEPH was stored in dry and dark place and dissolved in physiological saline $(0.9 \% \mathrm{NaCl})$ immediately before experiments.

\section{Dosage}

The doses for subcutaneous (sc.) administration were estimated with respect to the amounts usually used by humans, reported potency/affinity at transporters and based on our previous studies with related compounds especially MDMA, MDAI, and related ring-substituted cathinone methylone $(35,38,39,44,45)$. Furthermore, we set these doses with the intention to mimic the dosage comparable to human use and intermediate-high dose with expected strong acute effect, but non-lethal toxicity. Finally, the doses were also adequately adjusted for interspecies differences according the formula suggested by Reagan-Shaw et al. (46). All substances were dissolved in vehicle ( $0.9 \%$ physiological saline) at a volume of $2 \mathrm{ml} / \mathrm{kg}$ administered sc. (for comparability with our previous studies). Rats used for pharmacokinetic sampling were treated by MEPH $5 \mathrm{mg} / \mathrm{kg}$. MEPH 5 or $20 \mathrm{mg} / \mathrm{kg}$ was used in the temperature monitoring study, and MEPH 2.5, 5, or $20 \mathrm{mg} / \mathrm{kg}$ and nor-MEPH $5 \mathrm{mg} / \mathrm{kg}$ were used in behavioral tests. As vehicle controls (VEH) animals were treated with an equivalent volume of $0.9 \%$ physiological saline.

\section{Pharmacokinetics}

For pharmacokinetics, rats were administered MEPH ( $5 \mathrm{mg} / \mathrm{kg} \mathrm{sc}$.) and subsequently decapitated after $30,60,120,240$, or $480 \mathrm{~min}$ ( $n=8$ /experimental group). Sera, brain, liver, and lung tissues were collected and stored at $-20^{\circ} \mathrm{C}$ until analysis.

\section{Determination of MEPH and Nor-MEPH Levels in Serum and Tissue Samples Using LC/HRMS} Serum Pretreatment

$0.2 \mathrm{ml}$ of rat serum was fortified with the internal standard MEPH-D7 and nor-MEPH-D7 in methanolic solution (in an amount with respect to the levels of $\mathrm{MEPH} /$ nor-MEPH in assayed samples) and $0.5 \mathrm{ml}$ of a $0.1 \mathrm{M}$ phosphate buffer $(\mathrm{pH} \mathrm{6})$ in a labeled tube.

\section{Tissue Pretreatment}

$250 \mathrm{mg}$ of tissue (brain, lung, liver) was homogenized with $5 \mathrm{ml}$ methanol and the internal standard MEPH-D7 and nor-MEPHD7 (in an amount with respect to the MEPH/nor-MEPH levels in samples). Each specimen was then ultrasonicated for $20 \mathrm{~min}$ and after supernatant separation by centrifugation, the supernatant was transferred into a clean labeled tube and evaporated to dryness. The residue was reconstituted in $0.1 \mathrm{M}$ phosphate buffer ( $\mathrm{pH}$ 6). For solid-phase extraction (SPE) of MEPH/nor-MEPH, a pretreated sample of serum or tissue, along with the buffer and internal standard, was loaded onto a Bond Elut Certify cartridge previously conditioned with $0.5 \mathrm{ml}$ of $0.1 \mathrm{M}$ phosphate buffer $(\mathrm{pH} 6)$. After application of each pretreated sample, the cartridge was washed with $0.5 \mathrm{ml}$ of distilled water, $0.5 \mathrm{ml}$ of $0.1 \mathrm{M} \mathrm{HCl}$ and $0.5 \mathrm{ml}$ of $\mathrm{CH}_{3} \mathrm{OH} / \mathrm{H}_{2} \mathrm{O}(1 / 1, \mathrm{v} / \mathrm{v})$ and then air-dried for $5 \mathrm{~min}$. The analytes were eluted three times with $0.5 \mathrm{ml}$ of a freshly prepared mixture of dichloromethane/2-propanol/ammonium hydroxide (25\%), 80/20/4, v/v/v. The eluate was gently evaporated to dryness under a stream of air at $40^{\circ} \mathrm{C}$ and then dissolved into mobile phase for LC/HRMS analysis.

\section{LC/HRMS Conditions}

The analyses were performed using Dionex Ultimate 3000 UHPLC coupled to an Exactive Plus-Orbitrap MS (ThermoFisher Scientific, Bremen, Germany) equipped with a HESI-II source. The chromatographic analyses of the serum and tissue samples were performed using Kinetex PFP $100 \mathrm{~A}(50 \times 2.1 \mathrm{~mm}, 2.6 \mathrm{~mm})$ and Security Guard Cartridge PFP $4 \times 2.0 \mathrm{~mm}$ (Phenomenex) with a flow rate of $400 \mathrm{ml} / \mathrm{min}$, and gradient elution with $10 \mathrm{mM}$ 
ammonium formate in $0.1 \%$ of formic acid as the mobile phase B. Gradient 0 min 5\%, 4 min 45\% B, 5-6 min held at 95\%. The MS conditions were as follows: full MS in scan range of 50-500 $\mathrm{m} / \mathrm{z}$ with positive electrospray ionization, resolution of 70000 FWHM (full width at half-maximum, scan speed $3 \mathrm{~Hz}$ ), spray voltage of $3 \mathrm{kV}$, and an ion transfer capillary temperature of $320^{\circ} \mathrm{C}$.

\section{Behavior: Open Field and PPI Open Field}

The OFT was performed in accordance with our previous studies $(38,47)$. An empty black square arena $(68 \mathrm{~cm} \times 68 \mathrm{~cm} \times 30 \mathrm{~cm})$ was used, which was virtually divided into a $5 \times 5$ grid of identical squares; 16 squares were located near the arena walls (comprising the peripheral zone), and 9 squares were situated centrally (comprising the central zone). Rats were placed individually into the center of the arena 5 or 40 min after the drug administration (testing-onset) and their behavior was recorded for $30 \mathrm{~min}$ (nor-MEPH-treated rats were tested at the $5 \mathrm{~min}$ testing-onset only). The software EthoVision Color Pro v. 3.1.1 (Noldus, Netherlands) was used to capture the raw data used in the calculation of the following dependent variables: trajectory length $(\mathrm{cm}$; corrected for deviations of $<3 \mathrm{~cm}$ ) and its temporal dynamics in 5 min intervals; thigmotaxis $\left(\sum f_{\text {peripheral zones }} / \sum f_{\text {all zones, }}\right.$ where $f=$ frequency of appearance in the zone) reflects the probability of appearance in the peripheral zone; $T_{\text {center }}$ reflects time spent centrally $\left(\sum\right.$ time $\left._{\text {centralzones }}\right)$.

\section{Prepulse Inhibition}

Prepulse inhibition was evaluated in two identical startle chambers (SR-LAB, San Diego Instruments, CA, USA) each consisting of a sound-proof, evenly lit, ventilated enclosure with a Plexiglas stabilimeter $(8.7 \mathrm{~cm}$ inner diameter). The experimental design was adopted from our previous studies [e.g., Ref. (38, 41, 47)]. Briefly, 2 days before testing, rats were acclimatized to the startle chamber with a drug-free 5 min pre-training procedure consisting of 5 pulse alone stimuli $(115 \mathrm{~dB} / 20 \mathrm{~ms})$ presented over background white noise $(75 \mathrm{~dB})$. Startle data were not recorded for acclimatization. On the test day, the testing session was initiated 5 or $40 \mathrm{~min}$ after drug administration (only $5 \mathrm{~min}$ for nor-MEPH). The test session consisted of 72 trials in total with an inter-trial interval (ITI) of 4-20 s (mean ITI: $12.27 \mathrm{~s}$ ). After 5 min exposure to a continuous $75 \mathrm{~dB}$ background white noise, six $125 \mathrm{~dB} / 40 \mathrm{~ms}$ duration pulse alone trials were delivered to establish baseline ASR (for later calculation of habituation). Following this, 60 trials of the following were presented in a pseudorandom order: (A) pulse alone: $40 \mathrm{~ms} / 125 \mathrm{~dB}$; (B) prepulse-pulse: $20 \mathrm{~ms} / 83 \mathrm{~dB}$ or $20 \mathrm{~ms} / 91 \mathrm{~dB}$ prepulse with a variable $(30,60$, or $120 \mathrm{~ms}$ ) inter-stimulus interval (ISI: mean $=70 \mathrm{~ms}$ ), then $40 \mathrm{~ms} / 125 \mathrm{~dB}$ pulse; (C) $60 \mathrm{~ms}$ no stimulus. Finally, six pulse alone trials were delivered. Habituation was expressed as the percentage reduction in ASR from the initial six baseline trials, to the final six trials. PPI was calculated as follows: [100 - (mean prepulse - pulse trials/ mean pulse alone trials $) \times 100$ ]. Mean ASR was obtained from pulse alone trials. All measures were derived from the average of the area under the curve in arbitrary units (AVG). Animals with a mean ASR (AVG) response lower than 10 were excluded from analyses as non-responders.

\section{Body Temperature}

To evaluate the possible interactive effect of drugs and environmental conditions, we measured rectal temperatures in rats housed singly or in groups of five per cage. In total, 13 measurements were conducted as follows: three drug-free hourly measurements (07:00-09:00 h) followed by administration of (MEPH 5 or $20 \mathrm{mg} / \mathrm{kg}$ or $\mathrm{VEH})$ at $09: 00 \mathrm{~h}$, then four $30 \mathrm{~min}$ measurements $(09: 30-11: 00 \mathrm{~h})$, and finally six hourly measurements (12:00-17:00 h). A digital thermometer was used; each rat was briefly (max. $10 \mathrm{~s}$ ) immobilized in a Plexiglas tube during the procedure. Rats were kept under controlled laboratory conditions (temperature: $22 \pm 2{ }^{\circ} \mathrm{C}$, humidity: 30-70\%) in the experimental room throughout the study (which was where all temperature measurements were taken).

\section{Statistics}

All statistical analyses were performed using the data analysis software system STATISTICA version 9.1. [StatSoft, Inc. (2010)]. Tests used a default alpha set at $p=0.05$, two tailed. Behavioral and thermoregulation studies used factorial designs; therefore, analysis of variance (ANOVA) or analysis of covariance (ANCOVA) were used. Where these yielded significant main effects involving a factor with $>2$ levels or significant interactions, pair-wise post hoc comparisons were conducted using Newman-Keuls tests.

\section{Behavioral Data (OFT and PPI)}

Open field test spatial distribution (thigmotaxis and $T_{\text {center }}$ ) and PPI parameters (habituation, ASR, and PPI) were each analyzed using a $2 \times 4$ factorial ANOVA with testing-onset ( 5 or $40 \mathrm{~min}$ ) and drug treatment (VEH or MEPH 2.5, 5, and $20 \mathrm{mg} / \mathrm{kg} \mathrm{sc}$.) as between subjects factors. In the case of significant main effects on ASR or habituation, the significant factor was included as a covariate in subsequent analysis of PPI data (using ANCOVA). The temporal pattern of locomotor activity in the OFT (trajectory length in 5 min blocks) was analyzed using a $2 \times 4 \times 6$ mixed factorial ANOVA with testing-onset and drug treatment as between subjects factors, and time blocks $(6 \times 5 \mathrm{~min})$ as a within-subjects factor.

Additional analyses to compare the potency of nor-MEPH to $\mathrm{MEPH}$ were analyzed using one-way ANOVA with five drug treatment levels (VEH or nor-MEPH $5 \mathrm{mg} / \mathrm{kg}$ or MEPH 2.5, 5, and $20 \mathrm{mg} / \mathrm{kg} \mathrm{sc}$.) as a between-subjects factor. For the OFT, the temporal pattern of locomotor activity was analyzed using a $5 \times 6$ mixed factorial ANOVA with drug treatment as a between subjects factor and $5 \mathrm{~min}$ time blocks as a within subjects factor. Only data from the $5 \mathrm{~min}$ testing-onset were used in this analysis (because data for the 40 min testing-onset were not available for all drug treatments).

\section{Body Temperature}

Data were analyzed using $3 \times 2 \times 13$ mixed factorial design with drug treatment (VEH or MEPH 5 or $20 \mathrm{mg} / \mathrm{kg}$ ) and home-cage 
condition (singly- or group housed) as between subjects factors and time (13 measurements) as a within subjects factor.

\section{RESULTS}

\section{Pharmacokinetics}

The maximum mean MEPH serum concentration (826.2 ng/ml) was attained within $30 \mathrm{~min}$. Influx into the brain was not evidently delayed compared to serum; maximum mean concentration in the brain tissue $(767 \mathrm{ng} / \mathrm{g}$ ) was also attained by $30 \mathrm{~min}$ after the dose. MEPH robustly accumulated in lung: concentration at $30 \mathrm{~min}$ was $1,044.5 \mathrm{ng} / \mathrm{g}$, exceeding concentrations in sera, brain, and liver. Four hours after administration, the levels in sera and all tissues were almost undetectable (Figure 1A).

The maximum mean nor-MEPH (metabolized from $\mathrm{MEPH}$ in vivo; recall that nor-MEPH itself was not administered in pharmacokinetic studies) serum concentration of $351.9 \mathrm{ng} / \mathrm{ml}$ was attained within $1 \mathrm{~h}$ of treatment. The maximum mean concentration in the brain $(197.1 \mathrm{ng} / \mathrm{g})$ was also evident at $30 \mathrm{~min}$. Nor-MEPH accumulated in lung tissue with a maximum mean concentration of $382.9 \mathrm{ng} / \mathrm{g}$ observed at $30 \mathrm{~min}$. Six hours after administration, nor-MEPH was only slightly above the level of detection in all tissues and plasma (Figure 1B).

Mean brain: serum ratio was 1:1.19 for MEPH and 1:1.91 for nor-MEPH throughout the whole temporal observation.

\section{Behavior}

\section{Open Field Test}

Analysis of locomotion revealed a main effect of drug treatment $[F(3,72)=24.754, p<0.001]$, testing-onset $[F(1,72)=72.042$, $p<0.001]$ as well as blocks $[F(5,360)=101.67, p<0.001]$. All interactions were significant, including the three-way drug $\times$ testing-onset $\times$ blocks interaction [minimum $F(15,360)=2.979$, $p<0.001]$. The three-way interaction was explored further; at the 5 min testing-onset, while the normal pattern of locomotor habituation (i.e., a progressive decrease in activity over the session) was evident in all groups, post hoc tests showed that all MEPHtreated rats were hyperactive (compared to $\mathrm{VEH}$ ) across the six time blocks ( $p<0.001)$ (Figure 2A). At the 40 min testing-onset, elevated activity was no longer present $(p>0.05)$, although rats still showed normal locomotor habituation (Figure 2B). Additional analysis of total locomotion including nor-MEPH (5 min testingonset) confirmed a significant main effect of drug treatment $[F(4$, $45)=27.699, p<0.001]$, blocks $[F(5,225)=50.171, p<0.001]$, and their interaction $[F(20,225)=3.350, p<0.001]$. Post hoc tests showed that nor-MEPH $5 \mathrm{mg} / \mathrm{kg}$ rats displayed elevated activity (compared to VEH) across all six time blocks $(p<0.001)$ (Figure 2A). For typical trajectory patterns induced by the treatments see Figure 2C.

The effects of drug treatment, testing-onset, and their interaction were each significant for both $T_{\text {center }}$ [minimum $F(3,72)=5.385, p<0.01]$ and for thigmotaxis [minimum $F(3$, $72)=6.792, p<0.001]$. Additional one-way ANOVA analyses with nor-MEPH confirmed an effect of drug treatment on $T_{\text {center }}$ $[F(4,45)=26.845, p<0.001]$ and thigmotaxis $[F(4$, $45)=48.704, p<0.001]$. Post hoc tests showed that the 5-min testing-onset, MEPH 2.5 and $5 \mathrm{mg} / \mathrm{kg}$-treated rats spent more time in the center $(p<0.001)$ compared to VEH. Thigmotaxis was reduced after MEPH $5 \mathrm{mg} / \mathrm{kg}$ and nor-MEPH $5 \mathrm{mg} / \mathrm{kg}$ $(p<0.001)$, and increased after MEPH $20 \mathrm{mg} / \mathrm{kg}(p<0.001)$ (Figures 3A,B). No such significant effects were observed at the 40 min testing-onset (data not shown). Finally, MEPH $5 \mathrm{mg} /$ $\mathrm{kg}$ treated rats spent more time in the center $(p<0.001)$ and exhibited lower thigmotaxis $(p<0.001)$ at the 5 min compared to 40 min testing-onset; this pattern was absent in the rest of the groups (data not shown).

\section{Prepulse Inhibition}

Acoustic startle reaction was not affected by drug treatment or testing-onset, or their interaction [maximum $F(1,72)=3.322$, $p>0.05$; see Table 1]. Analysis of habituation data revealed a main effect of drug treatment $[F(3,72)=3.345, p<0.05]$; post hoc tests revealed reduced habituation in MEPH $2.5 \mathrm{mg} / \mathrm{kg}$ rats compared to VEH $(p<0.05)$; the other MEPH doses did not differ from VEH. There was also a significant main effect of testing-onset $[F(1,72)=6.405, p<0.05]$ manifested as
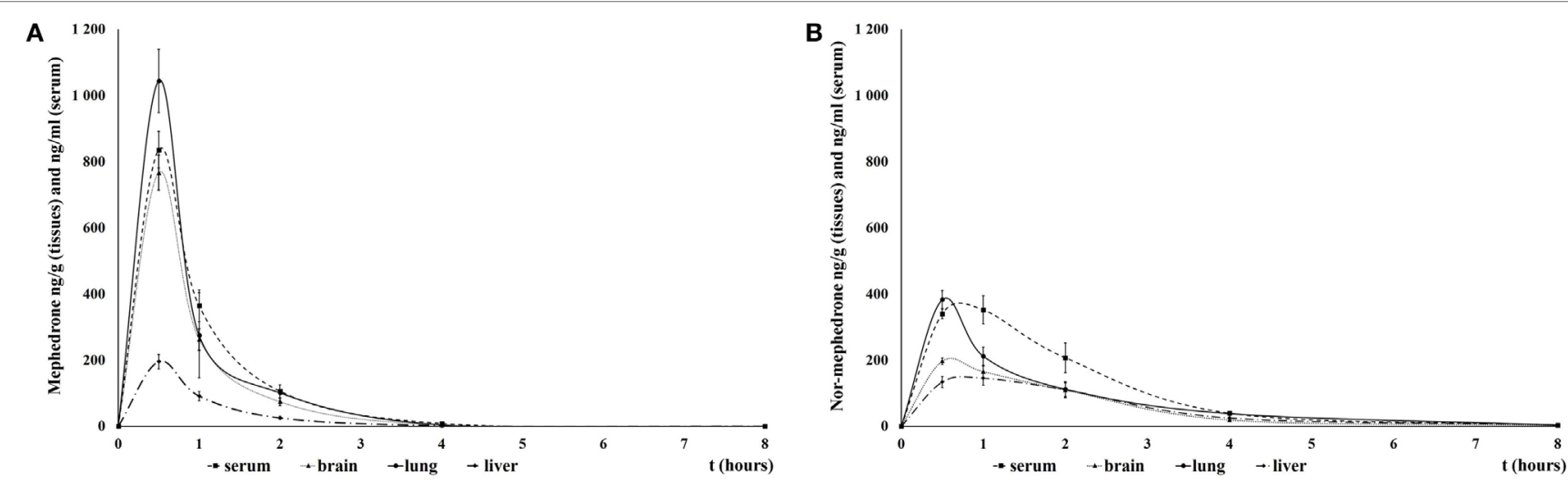

FIGURE 1 | Mean mephedrone (MEPH) (A) and its metabolite nor-mephedrone (B) levels in serum, brain, lungs, and liver over 6 h after application of MEPH 5 mg/ kg sc. Error bars display \pm 1 SEM. 

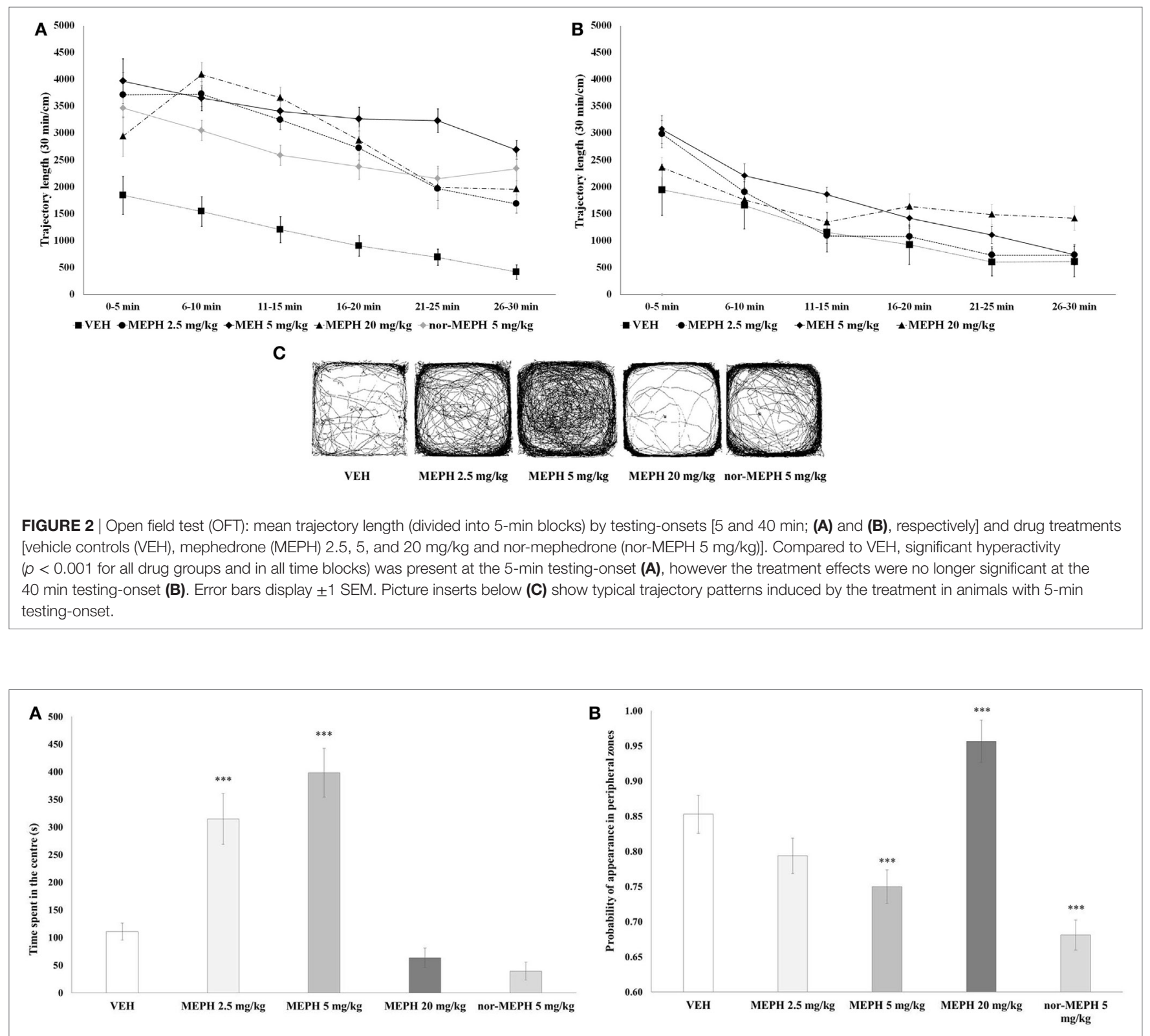

FIGURE 3 | Mean time spent in the arena center [T center, (A)] and mean probability of appearance in peripheral zones [thigmotaxis, (B)] after vehicle controls (VEH), mephedrone (MEPH) 2.5, 5 , and $20 \mathrm{mg} / \mathrm{kg}$, and nor-mephedrone (nor-MEPH) $5 \mathrm{mg} / \mathrm{kg}$ administered at the 5 -min testing-onset. MEPH 2.5 and $5 \mathrm{mg} / \mathrm{kg}$-treated rats spent significantly more time in the central zones compared to $\mathrm{VEH}$, and thigmotaxis was decreased by MEPH $5 \mathrm{mg} / \mathrm{kg}$ and nor-MEPH $5 \mathrm{mg} / \mathrm{kg}$, and increased by $\mathrm{MEPH} 20 \mathrm{mg} / \mathrm{kg}$. Error bars display $\pm 1 \mathrm{SEM} .{ }^{* \star *} p<0.001$ compared to VEH.

reduced habituation at the 5 min testing-onset compared to $40 \mathrm{~min}$. The drug treatment $\times$ testing-onset interaction was not significant.

Since there were significant effects of drug treatment and testing-onset on habituation, it was included as a covariate in PPI analyses. PPI was not affected by the drug treatment or testingonset, while their interaction was significant $[F(3,71)=3.483$, $p<0.05]$. At the $40 \mathrm{~min}$ testing-onset, means suggested some disruption of PPI (MEPH 5 and $20 \mathrm{mg} / \mathrm{kg}$ ); however, post hoc tests comparisons showed that differences from $\mathrm{VEH}$ were only marginal ( $p=0.062, p=0.081$, respectively). There were no clear differences in means (eye-balling the data) at $5 \mathrm{~min}$ that seemed likely to account for the significant interaction; since a further oneway ANOVA was planned to explore effects of MEPH (alongside nor-MEPH) on PPI, further post-hoc tests on the 5 min testingonset data were not conducted at this time. This additional oneway ANOVA showed no significant effect of treatment (MEPH or nor-MEPH) on PPI at the 5 min testing-onset $[F(4,45)=0.696$, $p>0.05]$; therefore, the marginal effects at $40 \mathrm{~min}$ must explain the previous interaction. Similarly, there was no effect of $\mathrm{MEPH}$ 
TABLE 1 | Mean values of acoustic startle reaction (ASR) amplitude and percentage of prepulse inhibition (PPI) after vehicle controls (VEH), mephedrone (MEPH), and nor-mephedrone (nor-MEPH) by testing-onsets (5 and $40 \mathrm{~min}$ ).

\begin{tabular}{|c|c|c|c|c|c|c|}
\hline \multirow[b]{2}{*}{ Measure } & \multirow[b]{2}{*}{ Testing-onsets (min) } & \multicolumn{5}{|c|}{ Drug treatment } \\
\hline & & VEH & $\begin{array}{c}\text { MEPH } \\
2.5 \mathrm{mg} / \mathrm{kg}\end{array}$ & $\begin{array}{c}\text { MEPH } \\
5 \mathrm{mg} / \mathrm{kg}\end{array}$ & $\begin{array}{c}\text { MEPH } \\
20 \mathrm{mg} / \mathrm{kg}\end{array}$ & $\begin{array}{c}\text { nor-MEPH } \\
5 \mathrm{mg} / \mathrm{kg}\end{array}$ \\
\hline \multirow[t]{2}{*}{ ASR } & 5 & 104.5 (14.3) & 117.5 (17.4) & $155.5(32.7)$ & 110.5 (14.2) & $72.1(11.5)$ \\
\hline & 40 & $137.2(20.0)$ & $140.8(26.4)$ & $144.6(22.3)$ & $173.9(24.8)$ & - \\
\hline \multirow[t]{2}{*}{$\%$ PPI } & 5 & $36.8(5.4)$ & $32.8(5.6)$ & $31.1(6.2)$ & $31.3(4.1)$ & $30.2(6.5)$ \\
\hline & 40 & $41.3(3.7)$ & $41.1(2.1)$ & $25.1(7.5)$ & 28.4 (3.3) & - \\
\hline
\end{tabular}

Numbers represent means and SEMs are shown in brackets. Differences between testing-onsets and drug treatments were non-significant.
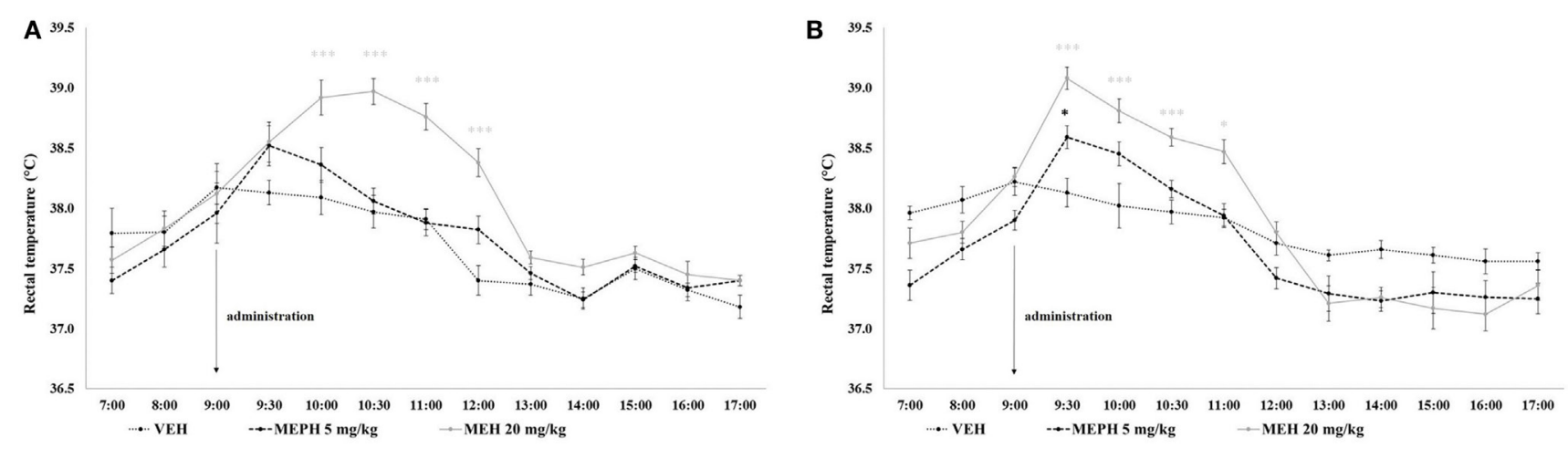

FIGURE 4 | Mean rectal temperature $\left({ }^{\circ} \mathrm{C}\right)$ over $10 \mathrm{~h}$ after vehicle control (VEH), and mephedrone (MEPH) 5 and $20 \mathrm{mg} / \mathrm{kg}$ treatments for rats housed singly (A) or in groups of five (B). Substances were administered at 09:00 h. Temperatures of rats treated by $5 \mathrm{mg} / \mathrm{kg}$ did not differ from VEH, except for the short-term elevation in the first $30 \mathrm{~min}$ after the administration in group-housed rats. The increase induced by $20 \mathrm{~kg} / \mathrm{kg}$ was maintained from 10:00 to $12: 00 \mathrm{~h}$ in singly housed rats and from 09:30 to 11:00 $\mathrm{h}$ in group-housed rats. Error bars display \pm 1 SEM. ${ }^{\star} p<0.05,{ }^{\star \star \star} p<0.001$ compared to VEH.

or nor-MEPH on ASR $[F(4,45)=2.454, p>0.05]$ or habituation $[F(4,45)=1.912, p>0.05]$ at the 5 -min testing-onset.

\section{Body Temperature}

Rectal temperature was significantly affected by drug treatment $[F(2,54)=9.409, p<0.001]$ and time $[F(12,648)=124.560$, $p<0.001]$ but not home-cage condition $[F(1,54)=0.127$, $p>0.05]$. All interactions were significant including the threeway drug treatment $\times$ time $\times$ home-cage interaction [minimum $F$ $(12,648)=2.406, p<0.010]$. Post-hoc tests revealed no significant differences between MEPH $5 \mathrm{mg} / \mathrm{kg}$ and $\mathrm{VEH}$ groups, except the elevation $\left(\sim 0.5^{\circ} \mathrm{C}\right)$ which occurred in the first $30 \mathrm{~min}$ after administration in group-housed rats $(p<0.05)$. Compared to $\mathrm{VEH}, \mathrm{MEPH} 20 \mathrm{mg} / \mathrm{kg}$ induced modest elevation $\left(\sim 0.4^{\circ} \mathrm{C}\right)$ in singly-housed rats that appeared in the first 30 min after administration; however, it became statistically significant 30 min later and the effect was maintained for the next $2 \mathrm{~h}\left(\sim 1^{\circ} \mathrm{C}\right.$; minimum $p<0.001)$. In group-housed rats, the elevation became significant within first $30 \mathrm{~min}$ and remained increased for next $2 \mathrm{~h}\left(\sim 1^{\circ} \mathrm{C}\right.$; minimum $p<0.001$ )-Figure 4 .

\section{DISCUSSION}

Mephedrone quickly peaked in the serum and was rapidly incorporated into all tissues, with lungs showing the highest concentrations and liver the lowest. MEPH was almost undetectable in serum and tissue by $4 \mathrm{~h}$ after its administration. Nor-MEPH had a similar profile; however the concentrations of nor-MEPH decreased more gradually in comparison to the parent drug (with $\mathrm{MEPH}$, a steep decrement occurred immediately after the peak). Therefore, compared to MEPH, the elimination of nor-MEPH was slightly delayed. Acute administration of both compounds resulted in dose-dependent stimulatory effects, disrupted habituation, and altered the spatial distribution of locomotor behavior in the open field; however, there was no significant effect on PPI. $\mathrm{MEPH}$ induced dose- and environment-dependent increases in rectal temperature (of up to $\sim 1^{\circ} \mathrm{C}$ ) in both group-housed rats (as expected), but also in singly housed rats, where temperature remained elevated for $3 \mathrm{~h}$ after administration of the highest MEPH dose.

\section{Pharmacokinetics}

In their study with iv. administration, Aarde et al. (29) showed that MEPH peaked in the brain within $2 \mathrm{~min}$; since the most pronounced locomotor effects in our study were present within 5-10 min of administration, it is likely that the peak concentration in serum also occurred earlier than suggested by our pharmacokinetic study (where the first measurement was at 30 min after the sc. administration). As expected, we detected the highest serum levels of both compounds in our dataset slightly 
earlier compared to oral administration, where $\mathrm{MEPH}$ peaked in serum within $45 \mathrm{~min}-1.5 \mathrm{~h}$ after administration (48). The speed of crossing the blood-brain barrier by MEPH implied by our current results was consistent with Aarde et al. (29); as shown by others (20), MEPH easily crosses blood-brain barrier and, thus, influx into brain and lung tissues is most likely due to its lipophilic profile. This finding is also consistent with the pharmacokinetics of another ring-substituted cathinone, methylone (39) as well as with the phenethylamines $2 \mathrm{C}-\mathrm{B}$ and PMMA, aminoindanes such as MDAI where highest tissue concentrations were detected in lungs and brains $(41,49,50)$. Not surprisingly, since nor-MEPH is not the only one major metabolite, it reached lower overall serum and tissue levels than the parent drug and the slope of its elimination was less steep, resulting in higher serum and brain concentrations compared to MEPH $3 \mathrm{~h}$ after its administration. One possible explanation could be the slightly higher polarity of nor-MEPH leading to slower crossing of the blood-brain barrier (30) and, theoretically, nor-MEPH may, therefore, be responsible for some delayed or prolonged effects of MEPH.

\section{Behavioral Effects: Open Field and PPI}

In line with pharmacokinetics, locomotor stimulant effects declined quickly, so MEPH and nor-MEPH lacked any significant stimulatory effects $40 \mathrm{~min}$ after administration. The rapid action of MEPH observed here is in line with other rodent studies (23, $28,30)$ and reports from human users (10). Since MEPH and nor-MEPH have both been shown to act on DAT $(23,30)$, it is most likely the underlying cause of these effects (51). MEPH and nor-MEPH seemed to be behaviorally equipotent. The fact that the effects lasted a very short time (due to fast kinetics) may increase the likelihood of re-dosing by humans and, together with its strongly reinforcing effects (shown in self-administration studies), indicates highly addictive characteristics (10).

Spatial characteristics of the trajectory after MEPH showed bi-directional effects dependent on the dose used. While increased exploration of the central zones following lower doses might imply decreased anxiety, increased thigmotaxis following the highest dose could suggest the opposite $(52,53)$. Compared to our findings, studies measuring anxiety using the elevated plus-maze (EPM) revealed contradictory results including either increased anxiety after acute treatment with low doses [0.25-10 mg/kg (54)], or no effect after sub-chronic MEPH treatment with very high doses $(30 \mathrm{mg} / \mathrm{kg}$ twice a day) $(55,56)$. Direct comparison of anxiety measures in the OFT versus EPM, however, may be difficult. While some authors report a good comparability (57) others have questioned this (58). In our study, spatial trajectory characteristics may be also affected by other mechanisms, such as increased stereotyped behaviors (e.g., circling the perimeter of the arena) such as was also observed in our previous studies with other related compounds $(38,41,47)$.

In accordance with previous research (31), we did not see any significant effect of acute MEPH or nor-MEPH on PPI. When our data are compared with similar data sets from phenethylamines, cathinones and aminoindanes performed in our laboratory, it is evident that that the more serotonergic the drug is [e.g., according to their DAT: SERT inhibition ratios (20)], the more pronounced the disruptive effect on PPI. While MDMA, PMMA, and MDAI significantly disrupted PPI at the lowest doses used $(35,38,41)$, which have mild-to-moderate stimulatory effects and do not induce stereotyped circling in the OFT, amphetamine and MDPV was effective only at the highest dose used where stereotyped behaviors were also evident [(37); unpublished observation Horsley et al.]. MEPH has also shown some activity at $5-\mathrm{HT}_{2 \mathrm{~A}}$ receptor (20), however, it is not clear whether it acts as agonist or antagonist. In relation to this, disruption of PPI is typically seen after administration of various $5-\mathrm{HT}_{2 \mathrm{~A}}$ agonists, serotonergic hallucinogens, such as LSD, mescaline, psilocybin, 2C-B or DOI, etc., and it is known that antagonists at this receptor can reinstate normal PPI (37, 59-63). Similarly, MDMA-induced PPI deficits in rats can be also normalized by 5-HT2A antagonists $(64,65)$, therefore suggesting a role for this receptor subtype in PPI; if MEPH acts as an antagonist at 5-HT2A receptors, this might theoretically be protective against psychomimesis.

\section{Temperature}

The hypothesis that MEPH, such as other cathinones (7), has a potency to alter thermoregulation was supported by evidence in our study. It is in line with reports of recreational users suffering from adverse effects related to altered peripheral thermoregulation, such as cold-blue fingers, hot flushes, and/or intensive sweating $(9,26)$. Likewise comparable preclinical studies [for review, see Green et al. (7)], we observed significant hyperthermia in both singly housed as well as group-housed rats under normal room temperature $\left(22 \pm 2^{\circ} \mathrm{C}\right)$. In contrast to our expectations, the temperature increase was almost identical $\left(\sim 1^{\circ} \mathrm{C}\right)$ in both groups but had slightly longer duration in singly housed rats. A possible explanation might be the faster onset of the temperature increase in the group-housed animals, where aggregation of animals in one cage would increase the microclimate temperature and in turn increase the speed of metabolism. The persistence of the temperature increase ( $3 \mathrm{~h}$ in singly housed rats), surprisingly, did not correspond with the rapid pharmacokinetic and locomotor profile of MEPH. Therefore additional factors, such as other active metabolite/s, may contribute to this prolonged effect and may indicate a potential for prolonged somatic drug toxicity, as in the case of toxic MDMA metabolites (66). In general, thermoregulation is mainly affected by drugs that primarily target serotonergic system [e.g., MDMA, PMMA, or MDAI $(38,41,67)$ ]. Dopaminergic stimulants may also increase body temperature (by increasing the behavioral activity), but effects are not as robust as with serotonergics (7). Direct comparisons of $\mathrm{MEPH}$ with other related cathinones, methylone $20 \mathrm{mg} / \mathrm{kg}$ sc., and MDPV $2 \mathrm{mg} / \mathrm{kg}$ sc. tested in our laboratory shows that the temperature increase was similar [(39); unpublished observation Horsley et al.]. This is of interest since the stimulant activity relative to the potency of the drug (DAT inhibition) should be approximately the same; however, the inhibition of SERT is much lower compared to DAT, and in the case of the lower MPDV dose would be approximately five times less effective (inhibiting SERT) than with MEPH or methylone (20). Taken together with the fact that the temperature increase was more prolonged in singly- than in group-housed rats and that it did not exceed $40^{\circ} \mathrm{C}$, we suggest that increases in the overall behavioral activity relevant to dopaminergic stimulation are responsible for the hyperthermia observed. However, 
against this interpretation, locomotor activation disappeared within 40 min of administration which is not consistent with the prolonged temperature increases. Further experiments will be needed in order to explain these discrepancies.

\section{CONCLUSION}

To conclude, both MEPH and nor-MEPH had rapid kinetics with accumulation in lungs and behaved as short-acting, potent stimulants with low capacity to disrupt sensorimotor gating. Dissociation between the duration of behavioral and hyperthermic effects may be due to the presence of another active metabolite with slower pharmacokinetic profile and may be indicative of prolonged risk of somatic toxicity even though acute stimulant-like effects have already worn off.

\section{ETHICS STATEMENT}

All procedures were conducted in accordance with the principles of laboratory animal care of the National Committee for the Care and Use of Laboratory Animals (Czech Republic), and according to Guidelines of the European Union (86/609/EU). The protocol

\section{REFERENCES}

1. Kelly BC. Legally tripping: a qualitative profile of salvia divinorum use among young adults. J Psychoactive Drugs (2011) 43:46-54. doi:10.1080/02791072.2 011.566500

2. Hill SL, Thomas SHL. Clinical toxicology of newer recreational drugs (vol 49, pg 705, 2011). Clin Toxicol (2011) 49:880-880. doi:10.3109/1556365 0.2011 .615318

3. Iversen L, Gibbons S, Treble R, Setola V, Huang X-P, Roth BL. Neurochemical profiles of some novel psychoactive substances. Eur J Pharmacol (2013) 700:147-51. doi:10.1016/j.ejphar.2012.12.006

4. Carhart-Harris RL, King LA, Nutt DJ. A web-based survey on mephedrone. Drug Alcohol Depend (2011) 118:19-22. doi:10.1016/j.drugalcdep.2011.02.011

5. Brunt T, Koeter M, Niesink R, Van Den Brink W. Linking the pharmacological content of ecstasy tablets to the subjective experiences of drug users. Psychopharmacology (2012) 220:751-62. doi:10.1007/s00213-011-2529-4

6. Varner KJ, Daigle K, Weed PF, Lewis PB, Mahne SE, Sankaranarayanan A, et al. Comparison of the behavioral and cardiovascular effects of mephedrone with other drugs of abuse in rats. Psychopharmacology (Berl) (2013) 225:675-85. doi:10.1007/s00213-012-2855-1

7. Green AR, King MV, Shortall SE, Fone KC. The preclinical pharmacology of mephedrone; not just MDMA by another name. Br J Pharmacol (2014) 171:2251-68. doi:10.1111/bph.12628

8. Karch SB. Cathinone neurotoxicity ("The "3Ms"). Curr Neuropharmacol (2015) 13:21-5. doi:10.2174/1570159X13666141210225009

9. Schifano F, Albanese A, Fergus S, Stair JL, Deluca P, Corazza O, et al. Mephedrone (4-methylmethcathinone; 'meow meow'): chemical, pharmacological and clinical issues. Psychopharmacology (Berl) (2011) 214:593-602. doi:10.1007/s00213-010-2070-x

10. Jones L, Reed P, Parrott A. Mephedrone and 3,4-methylenedioxy-methamphetamine: comparative psychobiological effects as reported by recreational polydrug users. J Psychopharmacol (2016) 30:1313-20. doi:10.1177/ 0269881116653106

11. Papaseit E, Moltó J, Muga R, Torrens M, De La Torre R, Farré M. Clinical pharmacology of the synthetic cathinone mephedrone. In: Baumann $\mathrm{MH}$, Glennon RA, Wiley JL, editors. Neuropharmacology of New Psychoactive Substances (NPS): The Science Behind the Headlines. Cham: Springer International Publishing (2017). p. 313-31. was approved by the National Committee for the Care and Use of Laboratory Animals (Czech Republic) under the number: MEYSCR-27527/2012-31.

\section{AUTHOR CONTRIBUTIONS}

All authors made a substantial contribution to the conception or design of the work; or the acquisition, analysis, or interpretation of data for the work. All authors were involved in drafting the work or revising it critically for important intellectual contents. All authors gave final approval for the current version of the work to be published. All authors agree to be accountable for all aspects of the work in ensuring that questions related to the accuracy or integrity of any part of the work are appropriately investigated and resolved.

\section{FUNDING}

This work was supported by projects VI20172020056, VG20122015075, PROGRES Q35, SVV260388, MH CZ-DRO (NIMH-CZ, 00023752), ED 2.1.00/03.0078 and grant LO1611 from the MEYS CR under the NPU I program.

12. EMCDDA, Europol. Europol-EMCDDA Joint Report on a New Psychoactive Substance: 4-Methylmethcathinone (Mephedrone). Lisbon: EMCDDA and Europol (2010).

13. Hope VD, Cullen KJ, Smith J, Jessop L, Parry J, Ncube F. Is the recent emergence of mephedrone injecting in the United Kingdom associated with elevated risk behaviours and blood borne virus infection? Euro Surveill (2016) 21:25-33. doi:10.2807/1560-7917.ES.2016.21.19.30225

14. Dickson AJ, Vorce SP, Levine B, Past MR. Multiple-drug toxicity caused by the coadministration of 4-methylmethcathinone (mephedrone) and heroin. J Anal Toxicol (2010) 34:162-8. doi:10.1093/jat/34.3.162

15. Schifano F, Corkery J, Ghodse AH. Suspected and confirmed fatalities associated with mephedrone (4-methylmethcathinone, "meow meow") in the United Kingdom. J Clin Psychopharmacol (2012) 32:710-4. doi:10.1097/ JCP.0b013e318266c70c

16. Loi B, Corkery JM, Claridge H, Goodair C, Chiappini S, Gimeno Clemente C, et al. Deaths of individuals aged 16-24 years in the UK after using mephedrone. Hum Psychopharmacol (2015) 30:225-32. doi:10.1002/hup.2423

17. Hockenhull J, Murphy KG, Paterson S. Mephedrone use is increasing in London. Lancet (2016) 387:1719-20. doi:10.1016/S0140-6736(16)30258-6

18. Wood DM, Dargan PI. Mephedrone (4-methylmethcathinone): what is new in our understanding of its use and toxicity. Prog Neuropsychopharmacol Biol Psychiatry (2012) 39:227-33. doi:10.1016/j.pnpbp.2012.04.020

19. Assi S, Gulyamova N, Kneller P, Osselton D. The effects and toxicity of cathinones from the users' perspectives: a qualitative study. Hum Psychopharmacol (2017) 32:7. doi:10.1002/hup.2610

20. Simmler LD, Buser TA, Donzelli M, Schramm Y, Dieu LH, Huwyler J, et al. Pharmacological characterization of designer cathinones in vitro. $\mathrm{Br}$ J Pharmacol (2013) 168:458-70. doi:10.1111/j.1476-5381.2012.02145.x

21. Liechti M. Novel psychoactive substances (designer drugs): overview and pharmacology of modulators of monoamine signaling. Swiss Med Wkly (2015) 145:w14043. doi:10.4414/smw.2015.14043

22. Pifl C, Reither H, Hornykiewicz O. The profile of mephedrone on human monoamine transporters differs from 3,4-methylenedioxymethamphetamine primarily by lower potency at the vesicular monoamine transporter. Eur J Pharmacol (2015) 755:119-26. doi:10.1016/j.ejphar.2015.03.004

23. Kehr J, Ichinose F, Yoshitake S, Goiny M, Sievertsson T, Nyberg F, et al. Mephedrone, compared with MDMA (ecstasy) and amphetamine, rapidly increases both dopamine and 5-HT levels in nucleus accumbens of 
awake rats. Br J Pharmacol (2011) 164:1949-58. doi:10.1111/j.1476-5381. 2011.01499.x

24. Baumann MH, Ayestas MA Jr, Partilla JS, Sink JR, Shulgin AT, Daley PF, et al. The designer methcathinone analogs, mephedrone and methylone, are substrates for monoamine transporters in brain tissue. Neuropsychopharmacology (2012) 37:1192-203. doi:10.1038/npp.2011.304

25. Dargan PI, Albert S, Wood DM. Mephedrone use and associated adverse effects in school and college/university students before the UK legislation change. QJM (2010) 103:875-9. doi:10.1093/qjmed/hcq134

26. Winstock A, Mitcheson L, Ramsey J, Davies S, Puchnarewicz M, Marsden J. Mephedrone: use, subjective effects and health risks. Addiction (2011) 106:1991-6. doi:10.1111/j.1360-0443.2011.03502.x

27. Hadlock GC, Webb KM, Mcfadden LM, Chu PW, Ellis JD, Allen SC, et al. 4-Methylmethcathinone (mephedrone): neuropharmacological effects of a designer stimulant of abuse. J Pharmacol Exp Ther (2011) 339:530-6. doi:10.1124/jpet.111.184119

28. Lisek R, Xu W, Yuvasheva E, Chiu YT, Reitz AB, Liu-Chen LY, et al. Mephedrone ('bath salt') elicits conditioned place preference and dopamine-sensitive motor activation. Drug Alcohol Depend (2012) 126:257-62. doi:10.1016/j. drugalcdep.2012.04.021

29. Aarde SM, Angrish D, Barlow DJ, Wright MJ Jr, Vandewater SA, Creehan KM, et al. Mephedrone (4-methylmethcathinone) supports intravenous selfadministration in Sprague-Dawley and Wistar rats. Addict Biol (2013) 18:786-99. doi:10.1111/adb.12038

30. MayerFP,WimmerL,Dillon-CarterO,PartillaJS,BurchardtNV,MihovilovicMD, et al. Phase I metabolites of mephedrone display biological activity as substrates at monoamine transporters. Br J Pharmacol (2016) 173:2657-68. doi:10.1111/bph.13547

31. Shortall SE, Macerola AE, Swaby RT, Jayson R, Korsah C, Pillidge KE, et al. Behavioural and neurochemical comparison of chronic intermittent cathinone, mephedrone and MDMA administration to the rat. Eur Neuropsychopharmacol (2013) 23:1085-95. doi:10.1016/j.euroneuro.2012.09.005

32. Geyer MA, Swerdlow NR. Measurement of startle response, prepulse inhibition, and habituation. Current Protocols in Neuroscience. John Wiley \& Sons, Inc. (2001). doi:10.1002/0471142301.ns0807s03

33. Martinez ZA, Ellison GD, Geyer MA, Swerdlow NR. Effects of sustained cocaine exposure on sensorimotor gating of startle in rats. Psychopharmacology (Berl) (1999) 142:253-60. doi:10.1007/s002130050887

34. Banjaw MY, Fendt M, Schmidt WJ. Clozapine attenuates the locomotor sensitisation and the prepulse inhibition deficit induced by a repeated oral administration of Catha edulis extract and cathinone in rats. Behav Brain Res (2005) 160:365-73. doi:10.1016/j.bbr.2005.01.002

35. Bubenikova V, Votava M, Horacek J, Palenicek T. Relation of sex and estrous phase to deficits in prepulse inhibition of the startle response induced by ecstasy (MDMA). Behav Pharmacol (2005) 16:127-30. doi:10.1097/ 00008877-200503000-00009

36. Horrillo R, Gonzalez-Periz A, Martinez-Clemente M, Lopez-Parra M, Ferre N, Titos E, et al. 5-Lipoxygenase activating protein signals adipose tissue inflammation and lipid dysfunction in experimental obesity. J Immunol (2010) 184:3978-87. doi:10.4049/jimmunol.0901355

37. Palenicek T, Fujakova M, Brunovsky M, Horacek J, Gorman I, Balikova M, et al. Behavioral, neurochemical and pharmaco-EEG profiles of the psychedelic drug 4-bromo-2,5-dimethoxyphenethylamine (2C-B) in rats. Psychopharmacology (2013) 225:75-93. doi:10.1007/s00213-012-2797-7

38. Palenicek T, Lhotkova E, Zidkova M, Balikova M, Kuchar M, Himl M, et al. Emerging toxicity of 5,6-methylenedioxy-2-aminoindane (MDAI): pharmacokinetics, behaviour, thermoregulation and LD50 in rats. Prog Neuropsychopharmacol Biol Psychiatry (2016) 69:49-59. doi:10.1016/j.pnpbp. 2016.04.004

39. Štefková K, Židková M, Horsley RR, Pinterová N, Šíchová K, Uttl L, et al. Pharmacokinetic, ambulatory, and hyperthermic effects of 3,4-methylenedioxyN-methylcathinone (methylone) in rats. Front Psychiatry (2017) 8:232. doi:10.3389/fpsyt.2017.00232

40. Shortall SE, Spicer CH, Ebling FJ, Green AR, Fone KC, King MV. Contribution of serotonin and dopamine to changes in core body temperature and locomotor activity in rats following repeated administration of mephedrone. Addict Biol (2015) 21:1127-39. doi:10.1111/adb.12283

41. Palenicek T, Balikova M, Rohanova M, Novak T, Horacek J, Fujakova M, et al. Behavioral, hyperthermic and pharmacokinetic profile of para- methoxymethamphetamine (PMMA) in rats. Pharmacol Biochem Behav (2011) 98:130-9. doi:10.1016/j.pbb.2010.12.011

42. Parrott AC. MDMA and temperature: a review of the thermal effects of 'ecstasy' in humans. Drug Alcohol Depend (2012) 121:1-9. doi:10.1016/j. drugalcdep.2011.08.012

43. Halpern P, Moskovich J, Avrahami B, Bentur Y, Soffer D, Peleg K. Morbidity associated with MDMA (ecstasy) abuse: a survey of emergency department admissions. Hum Exp Toxicol (2011) 30:259-66. doi:10.1177/0960327110 370984

44. Palenicek T, Votava M, Bubenikova V, Horacek J. Increased sensitivity to the acute effects of MDMA ("ecstasy") in female rats. Physiol Behav (2005) 86:546-53. doi:10.1016/j.physbeh.2005.08.043

45. Palenicek T, Hlinak Z, Bubenikova-Valesova V, Votava M, Horacek J. An analysis of spontaneous behavior following acute MDMA treatment in male and female rats. Neuro Endocrinol Lett (2007) 28:781-8.

46. Reagan-Shaw S, Nihal M, Ahmad N. Dose translation from animal to human studies revisited. FASEB J (2008) 22:659-61. doi:10.1096/fj.07-9574LSF

47. Horsley RR, Lhotkova E, Hajkova K, Jurasek B, Kuchar M, Palenicek T. Detailed pharmacological evaluation of methoxetamine (MXE), a novel psychoactive ketamine analogue - behavioural, pharmacokinetic and metabolic studies in the Wistar rat. Brain Res Bull (2016) 126:102-10. doi:10.1016/j. brainresbull.2016.05.002

48. Martinez-Clemente J, Lopez-Arnau R, Carbo M, Pubill D, Camarasa J, Escubedo E. Mephedrone pharmacokinetics after intravenous and oral administration in rats: relation to pharmacodynamics. Psychopharmacology (Berl) (2013) 229:295-306. doi:10.1007/s00213-013-3108-7

49. Rohanova M, Palenicek T, Balikova M. Disposition of 4-bromo-2,5-dimethoxyphenethylamine (2C-B) and its metabolite 4-bromo-2-hydroxy-5methoxyphenethylamine in rats after subcutaneous administration. Toxicol Lett (2008) 178:29-36. doi:10.1016/j.toxlet.2008.01.017

50. Hajkova K, Jurasek B, Sykora D, Palenicek T, Miksatkova P, Kuchar M. Saltingout-assisted liquid-liquid extraction as a suitable approach for determination of methoxetamine in large sets of tissue samples. Anal Bioanal Chem (2016) 408:1171-81. doi:10.1007/s00216-015-9221-1

51. Beninger RJ. The role of dopamine in locomotor activity and learning. Brain Res (1983) 287:173-96. doi:10.1016/0165-0173(83)90038-3

52. Archer J. Tests for emotionality in rats and mice: a review. Anim Behav (1973) 21:205-35. doi:10.1016/S0003-3472(73)80065-X

53. Walsh RN, Cummins RA. The open-field test: a critical review. Psychol Bull (1976) 83:482-504. doi:10.1037/0033-2909.83.3.482

54. Budzynska B, Boguszewska-Czubara A, Kruk-Slomka M, Kurzepa J, Biala G. Mephedrone and nicotine: oxidative stress and behavioral interactions in animal models. Neurochem Res (2015) 40:1083-93. doi:10.1007/ s11064-015-1566-5

55. Den Hollander B, Rozov S, Linden AM, Uusi-Oukari M, Ojanpera I, Korpi ER. Long-term cognitive and neurochemical effects of "bath salt" designer drugs methylone and mephedrone. Pharmacol Biochem Behav (2013) 103:501-9. doi:10.1016/j.pbb.2012.10.006

56. Motbey CP, Clemens KJ, Apetz N, Winstock AR, Ramsey J, Li KM, et al. High levels of intravenous mephedrone (4-methylmethcathinone) selfadministration in rats: neural consequences and comparison with methamphetamine. J Psychopharmacol (2013) 27:823-36. doi:10.1177/0269881113 490325

57. Cannizzaro C, Plescia F, Gagliano M, Cannizzaro G, Mantia G, Labarbera M, et al. Perinatal exposure to 5-metoxytryptamine, behavioural-stress reactivity and functional response of 5-HT1A receptors in the adolescent rat. Behav Brain Res (2008) 186:98-106. doi:10.1016/j.bbr.2007.07.036

58. Lalonde R, Strazielle C. Relations between open-field, elevated plus-maze, and emergence tests in C57BL/6J and BALB/c mice injected with GABAand 5HT-anxiolytic agents. Fundam Clin Pharmacol (2010) 24:365-76. doi:10.1111/j.1472-8206.2009.00772.x

59. Geyer MA, Krebs-Thomson K, Braff DL, Swerdlow NR. Pharmacological studies of prepulse inhibition models of sensorimotor gating deficits in schizophrenia: a decade in review. Psychopharmacology (2001) 156:117-54. doi:10.1007/s002130100811

60. Palenicek T, Balikova M, Bubenikova-Valesova V, Horacek J. Mescaline effects on rat behavior and its time profile in serum and brain tissue after a single subcutaneous dose. Psychopharmacology (Berl) (2008) 196:51-62. doi:10.1007/s00213-007-0926-5 
61. Palenicek T, Hlinak Z, Bubenikova-Valesova V, Novak T, Horacek J. Sex differences in the effects of N,N-diethyllysergamide (LSD) on behavioural activity and prepulse inhibition. Prog Neuropsychopharmacol Biol Psychiatry (2010) 34:588-96. doi:10.1016/j.pnpbp.2010.02.008

62. Nichols DE. Psychedelics. Pharmacol Rev (2016) 68:264-355. doi:10.1124/ pr.115.011478

63. Tyls F, Palenicek T, Kaderabek L, Lipski M, Kubesova A, Horacek J. Sex differences and serotonergic mechanisms in the behavioural effects of psilocin. Behav Pharmacol (2016) 27:309-20. doi:10.1097/FBP.0000000000000198

64. Kehne JH, Padich RA, Mccloskey TC, Taylor VL, Schmidt CJ. 5-HT modulation of auditory and visual sensorimotor gating: I. Effects of 5-HT releasers on sound and light prepulse inhibition in Wistar rats. Psychopharmacology (Berl) (1996) 124:95-106. doi:10.1007/BF02245609

65. Padich RA, Mccloskey TC, Kehne JH. 5-HT modulation of auditory and visual sensorimotor gating: II. Effects of the 5-HT2A antagonist MDL 100,907 on disruption of sound and light prepulse inhibition produced by 5 -HT agonists in Wistar rats. Psychopharmacology (Berl) (1996) 124:107-16. doi:10.1007/ BF02245610
66. Kalant $\mathrm{H}$. The pharmacology and toxicology of "ecstasy" (MDMA) and related drugs. Can Med Assoc J (2001) 165:917-28.

67. Green AR, O'shea E, Saadat KS, Elliott JM, Colado MI. Studies on the effect of MDMA ('ecstasy') on the body temperature of rats housed at different ambient room temperatures. Br J Pharmacol (2005) 146:306-12. doi:10.1038/ sj.bjp. 0706318

Conflict of Interest Statement: The authors declare that the research was conducted in the absence of any commercial or financial relationships that could be construed as a potential conflict of interest.

Copyright @ 2018 Šichová, Pinterová, Židková, Horsley, Lhotková, Štefková, Vejmola, Uttl, Baliková, Kuchař and Páleníček. This is an open-access article distributed under the terms of the Creative Commons Attribution License (CC BY). The use, distribution or reproduction in other forums is permitted, provided the original author(s) or licensor are credited and that the original publication in this journal is cited, in accordance with accepted academic practice. No use, distribution or reproduction is permitted which does not comply with these terms. 